\title{
Implications of a bioresorbable vascular scaffold implantation on vessel wall strain of the treated and the adjacent segments
}

\author{
Christos V. Bourantas · Hector M. Garcia-Garcia - Carlos A. M. Campos • \\ Yao-Jun Zhang · Takashi Muramatsu • Marie-Angèle Morel · Shimpei Nakatani • \\ Xingyu Gao • Yun-Kyeong Cho • Yuki Isibashi • Frank J. H. Gijsen • \\ Yoshinobu Onuma $\cdot$ Patrick W. Serruys
}

Received: 26 September 2013/Accepted: 15 January 2014/Published online: 24 January 2014

(C) Springer Science+Business Media Dordrecht 2014

\begin{abstract}
Background Metallic stents change permanently the mechanical properties of the vessel wall. However little is known about the implications of bioresorbable vascular scaffolds (BVS) on the vessel wall strain. Methods Patients $(\mathrm{n}=53)$ implanted with an Absorb BVS that had palpographic evaluation at any time point [before device implantation, immediate after treatment, at short-term (6-12 months) or mid-term follow-up (24-36 months)] were included in the current analysis. The palpographic data were used to estimate the mean of the maximum strain values and the obtained measurements were classified using the Rotterdam classification (ROC) score and expressed as ROC/mm. Results Scaffold implantation led to a significant decrease of the vessel wall strain in the treated segment $[0.35(0.20,0.38)$ vs. $0.19(0.09,0.29)$; $P=0.005]$ but it did not affect the proximal and distal edge. In patients who had serial palpographic examination the vessel wall strain continued to decrease in the scaffolded segment at short-term $[0.20(0.12,0.29)$ vs. 0.14 $(0.08,0.20) ; P=0.048]$ and mid-term follow-up [0.20
\end{abstract}

On behalf of the Absorb Cohort B Investigators.

Electronic supplementary material The online version of this article (doi:10.1007/s10554-014-0373-4) contains supplementary material, which is available to authorized users.

C. V. Bourantas - H. M. Garcia-Garcia - C. A. M. Campos ·

Y.-J. Zhang - T. Muramatsu · M.-A. Morel · S. Nakatani ·

Y.-K. Cho · Y. Isibashi · F. J. H. Gijsen - Y. Onuma ·

P. W. Serruys $(\bowtie)$

Interventional Cardiology Department, Thoraxcenter, Erasmus

Medical Center, 's-Gravendijkwal 230, 3015, CE, Rotterdam,

The Netherlands

e-mail: p.w.j.c.serruys@erasmusmc.nl

X. Gao

Abbott Vascular, Santa Clara, CA, USA
$(0.12,0.29)$ vs. $0.15(0.10,0.19), P=0.024]$. No changes were noted with time in the mechanical properties of the vessel wall at the proximal and distal edge. Conclusions Absorb BVS implantation results in a permanent alteration of the mechanical properties of the vessel wall in the treated segment. Long term follow-up data are needed in order to examine the clinical implications of these findings.

Keywords Bioresorbable vascular scaffold .

Palpography $\cdot$ Vessel wall strain

\section{Introduction}

Vessel wall mechanical behavior appears to be associated with the compositional characteristics of the plaque and predict future cardiovascular events [1-4]. Several studies have shown that pharmaceutical or an interventional treatment can influence the mechanical properties of the vessel wall by altering its constituents [5-9]. Following an endoluminal device implantation (i.e., a metallic stent or a bioresorbable scaffold) the local vessel wall strain of the implanted segment is reduced and this has been attributed to the increased stiffness of the deployed device [5, 6, 9].

Recently we have reported the results of the palpographic analysis performed in segments implanted with the updated revision of the Absorb bioresorbable vascular scaffold (BVS) 1.1 [6]. We found that the vessel wall strain is reduced in the scaffolded segments immediately after device deployment but there are no further changes in the mechanical properties of the vessel wall between postscaffold implantation and at short-term follow-up (i.e., at 6-12 months). The present analysis aims to investigate the mid-term implications (i.e., at 24-36 months) of the Absorb BVS 1.1 on the vessel wall strain. 


\section{Methods}

Included patients and study design

The ABSORB Cohort B trial (A Clinical Evaluation of the Bioabsorbable Everolimus Eluting Coronary Stent System the Treatment of Patients with de Novo Native Coronary Artery Lesions) was a prospective multicenter single-arm study designed to investigate the safety and efficacy of the Absorb BVS 1.1 (Abbott Vascular, Santa Clara, CA, USA) [10]. One hundred one patients were included in this study and were divided in two groups (B1 and B2). The first group had invasive imaging evaluation [i.e., coronary angiography, grayscale intravascular ultrasound (IVUS), IVUS virtual histology, palpographic and optical coherence tomographic imaging] at baseline, 6 months and 2 years follow-up; while the second group had the abovementioned invasive tests at baseline, 1 year and at 3 years follow-up. Optical coherence tomographic (OCT) examination was optional and was not performed in all the studied patients. The current analysis included only the patients who had a palpographic assessment at least at one time point. The Absorb Cohort B study was sponsored and financially supported by Abbott Vascular.

The Absorb BVS 1.1 used in the ABSORB Cohort B trial, is a fully bioresorbable device with dimensions $3.0 \times 18 \mathrm{~mm}$. The composition of the device consists of poly-L-lactide (PLLA) that is covered by an thin layer of an amorphous matrix of poly-D,L-lactide (PDLLA) which contains and controls the release of the anti-proliferative drug everolimus (concentration: $100 \mu \mathrm{g} / \mathrm{cm}^{2}$ ). The Absorb BVS 1.1 has an in-phase zigzag hoops linked with bridges design that provides the device increased radial strength and eliminates the risk of late scaffold recoil, while the polymer of this revision has been processed in such a way so as to have a delayed degradation (by approximately 18 months comparing to the 1 st revision).

The palpographic sub-study of the ABSORB Cohort B trial had pre-specified hypotheses. In particular the investigators expected that the delayed degradation in Absorb BVS 1.1 would result: either (1) in a delayed restoration of the normal, pre-scaffold implantation, strain, or (2) it would allow the built up of neointima tissue that would permanently alter the mechanical properties of the vessel wall.

IVUS acquisition and analysis

Intravascular ultrasound imaging was performed in the treated artery using an Eagle Eye $20 \mathrm{MHz}$ imaging catheter (acquisition frame rate 30 frames/s, Volcano Corp, Rancho Cordova, CA, USA) that was withdrawn with the use of an automated pull-back device at a speed of $0.5 \mathrm{~mm} / \mathrm{s}$. During
IVUS examination the electrocardiogram and the aortic pressure were recorded.

The radiofrequency IVUS imaging data were acquired using a custom design workstation and were transferred to an independent clinical research organization (Cardialysis, Rotterdam, the Netherlands) for offline analysis. For each studied artery the IVUS images portraying the $5 \mathrm{~mm}$ proximal, the scaffolded, and the $5 \mathrm{~mm}$ distal segment were analyzed. The local strain was estimated from the radiofrequency IVUS data using cross correlation analysis according to a previously described methodology [11]. The measured strain values were displayed in spread-out vessel plots using a color coded map with the blue indicating low strain values and the red/yellow a high strain (range 0-2 \%) [11].

The strain values were classified according to the Rotterdam classification (ROC) score to four classes (ROC I: $0-0.5 \%$, ROC II: $0.6-<0.9 \%$, ROC III: $0.9-<1.2 \%$ and ROC IV: $>1.2 \%$ ). A cross section was considered to have high strain when the measured strain was classified as ROC III-IV in an $\operatorname{arc}$ of $>12^{\circ}$. For each cross section the highest strain value was recorded and considered as the strain of this section. The mean of the maximum strain values measured in each segment was determined and used to characterize the strain of the segment. Results are presented as ROC/mm (Fig. 1).

\section{Statistics}

Continuous variables depending on their distribution are presented as mean \pm standard deviation or as median with 25 th and 75th percentiles, as indicated in the tables. Categorical variables are presented as absolute values and percentages. Because of the small number of patients who had palpographic evaluation at different time points we merged the data from Cohort B1 and B2 and present our results at 4 time points: at baseline pre-scaffold implantation, immediately after scaffold implantation, at short-term (6-12 months), and at mid-term follow-up (24-36 months). Comparison between the two cohorts was done by $t$ test and Chi square test, or Fisher's exact test when Cochran's rule is not met.

Changes in the strain values between two different time points were evaluated by means of paired Wilcoxon singed rank test. A $\mathrm{P}$ value $<0.05$ (two-tailed) was considered statistically significant. Data analysis was performed using the SAS statistical computer package (SAS 9.2, SAS Institute Inc., Cary, NC, USA).

\section{Results}

Studied population

Fifty-three from the 101 patients who were enrolled in the Absorb Cohort B study had palpographic evaluation at 


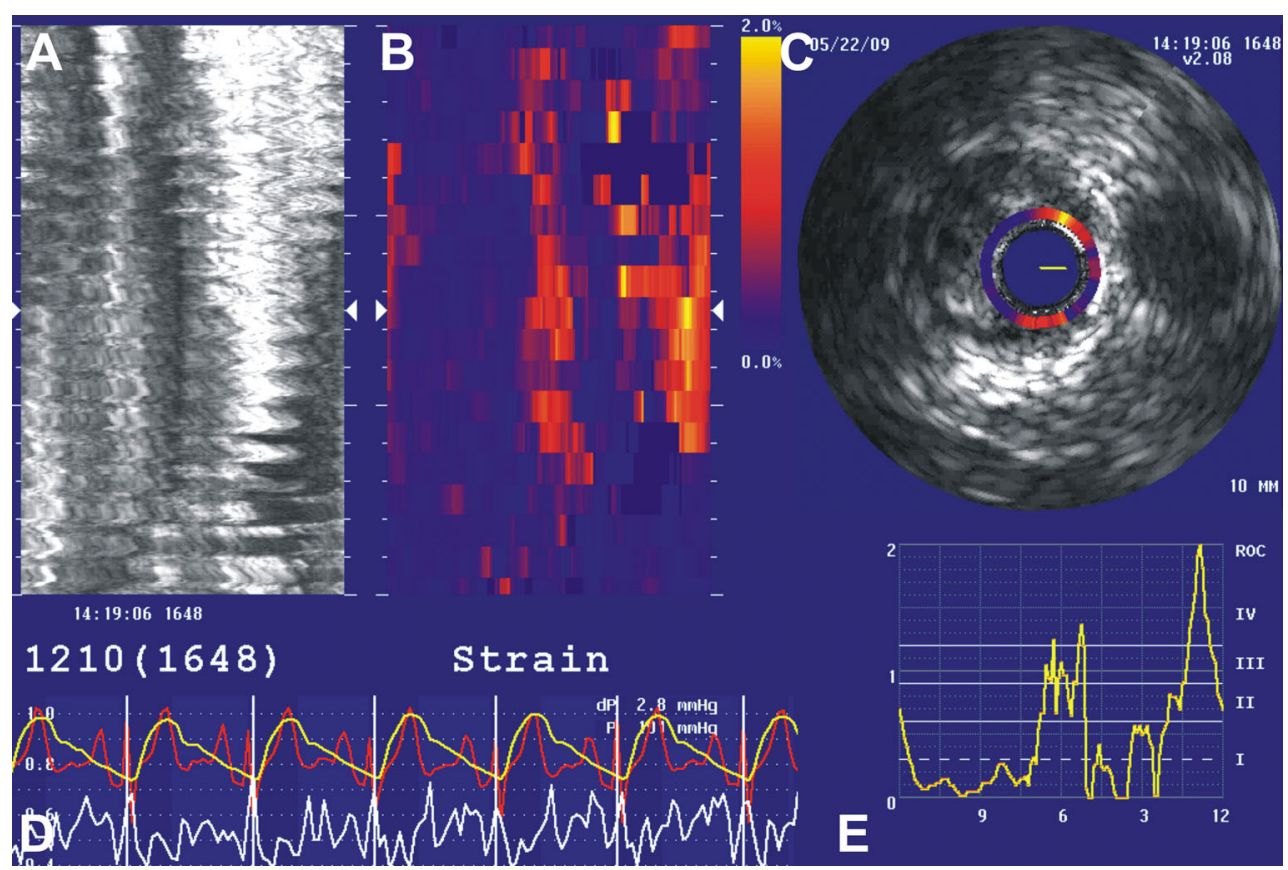

Fig. 1 Snapshot showing the palpographic evaluation of a lesion before scaffold implantation. Panel $A$ shows a longitudinal IVUS cross-section of the studied segment while panel $B$ a spread out plot of the measured vessel wall strain (the blue color indicates low strain and the red/yellow high strain values). An IVUS cross section with the estimated strain at the superficial plaque shown in color coding is portrayed in panel $C$. Panel $D$ shows the electrocardiogram, the measured strain, and the blood pressure changes during the cardiac circle throughout the pull-back of the catheter, whereas panel $E$ displays the strain values measured in the cross-section shown in panel $C$. High strain was noted at 1 and 6 o'clock

deployment $(P=0.814$ for the short-term follow-up and $P=0.162$ for the mid-term follow-up). However, when we compared the follow-up values at the proximal edge with the strain measured immediately after scaffold deployment we found statistical significant differences (Table 2). At the distal edge the strain values did not change with time.

The strain values in the scaffolded segment at the two follow-up time points were considerably lower comparing to baseline before device implantation $(P=0.002$ for the short-term and $P=0.001$ for the mid-term follow-up) but they were not different from these measured immediately after scaffold deployment.

When we included in our analysis only the segments ( $\mathrm{n}=20$ patients) that had serial palpographic examination (i.e., at baseline immediate after device deployment, at shortterm, and at mid-term follow-up) we found that the strain of the proximal edge and distal edge did not change with time (Table 3; Fig. 2). On the other hand in the scaffolded segment the strain values were significantly decreased at shortand mid-term follow-up comparing to baseline.

\section{Discussion}

In this study we examined for the first time the implications of the second revision Absorb BVS on the mechanical edge at the two follow-up time points was different from the vessel wall strain before scaffold 
Table 1 Baseline demographics, angiographic characteristics and medications of the studied population

\begin{tabular}{|c|c|c|c|c|}
\hline Patients' demographics & $\begin{array}{l}\text { Absorb Cohort B } \\
\mathrm{N}=53\end{array}$ & $\begin{array}{l}\text { Absorb Cohort B1 } \\
\mathrm{N}=20\end{array}$ & $\begin{array}{l}\text { Absorb Cohort B2 } \\
\mathrm{N}=33\end{array}$ & $P$ \\
\hline Age (years) & $61.28 \pm 8.41$ & $63.84 \pm 8.87$ & $59.72 \pm 7.85$ & 0.096 \\
\hline Male & $71.7 \%(38 / 53)$ & $75.0 \%(15 / 20)$ & $69.7 \%(23 / 33)$ & 0.678 \\
\hline Hypertension & $67.3 \%(35 / 52)$ & $60.0 \%(12 / 20)$ & $71.9 \%(23 / 32)$ & 0.374 \\
\hline Hypercholesterolemia & $83.0 \%(44 / 53)$ & $100.0 \%(20 / 20)$ & $72.7 \%(24 / 33)$ & 0.010 \\
\hline Diabetes & $18.9 \%(10 / 53)$ & $15.0 \%(3 / 20)$ & $21.2 \%(7 / 33)$ & 0.725 \\
\hline Current smoking & $15.1 \%(8 / 53)$ & $0.0 \%(0 / 20)$ & $24.2 \%(8 / 33)$ & 0.019 \\
\hline Prior PCI & $22.6 \%(12 / 53)$ & $25.0 \%(5 / 20)$ & $21.2 \%(7 / 33)$ & 0.748 \\
\hline Stable angina & $73.6 \%(39 / 53)$ & $90.0 \%(18 / 20)$ & $63.6 \%(21 / 33)$ & 0.035 \\
\hline Unstable angina & $9.4 \%(5 / 53)$ & $5.0 \%(1 / 20)$ & $12.1 \%(4 / 33)$ & 0.639 \\
\hline Silent ischemia & $1.9 \%(1 / 53)$ & $0.0 \%(0 / 20)$ & $3.0 \%(1 / 33)$ & 1.000 \\
\hline \multicolumn{5}{|l|}{ Treated vessel } \\
\hline Left anterior descending & $47.2 \%(25 / 53)$ & $45.0 \%(9 / 20)$ & $48.5 \%(16 / 33)$ & 0.805 \\
\hline Left circumflex & $24.5 \%(13 / 53)$ & $25.0 \%(5 / 20)$ & $24.2 \%(8 / 33)$ & 1.000 \\
\hline Right coronary artery & $28.3 \%(15 / 53)$ & $30.0 \%(6 / 20)$ & $27.3 \%(9 / 33)$ & 0.831 \\
\hline \multicolumn{5}{|l|}{ QCA analysis pre-treatment } \\
\hline $\mathrm{RVD}(\mathrm{mm})$ & $2.61 \pm 0.34$ & $2.60 \pm 0.44$ & $2.61 \pm 0.28$ & 0.949 \\
\hline $\operatorname{MLD}(\mathrm{mm})$ & $1.04 \pm 0.27$ & $0.99 \pm 0.31$ & $1.07 \pm 0.23$ & 0.365 \\
\hline Diameter stenosis (\%) & $59.80 \pm 9.96$ & $61.25 \pm 12.74$ & $58.94 \pm 7.98$ & 0.482 \\
\hline \multicolumn{5}{|l|}{ Medications } \\
\hline$\beta$-blockers & $73.6 \%$ (39) & $65.0 \%(13)$ & $78.8 \%(26)$ & 0.270 \\
\hline RAAS inhibitors & $69.8 \%(37)$ & $65.0 \%(13)$ & $72.7 \%(24)$ & 0.443 \\
\hline Statins & $94.3 \%(50)$ & $100.0 \%(20)$ & $90.9 \%(30)$ & 0.165 \\
\hline
\end{tabular}

$P C I$ percutaneous coronary intervention, $Q C A$ quantitative coronary angiography, $R V D$ reference vessel diameter, $M L D$ minimum luminal diameter, RAAS renin angiotensin aldosterone system

Table 2 Strain values at the proximal edge, the scaffolded segment and the distal edge before device implantation, immediately after device deployment, at short-term follow-up and at mid-term follow-up

\begin{tabular}{|c|c|c|c|c|c|c|c|c|}
\hline & $\begin{array}{l}\text { Pre-scaffold } \\
\text { implantation }(n=14)\end{array}$ & $\begin{array}{l}\text { Post-scaffold } \\
\text { implantation }(\mathrm{n}=44)\end{array}$ & $P_{1}$ & $\begin{array}{l}\text { Short term follow- } \\
\text { up }(n=41)\end{array}$ & $\begin{array}{l}\text { Mid-term follow- } \\
\text { up }(n=36)\end{array}$ & $P_{2}$ & $P_{3}$ & $P_{4}$ \\
\hline $\begin{array}{l}\text { Proximal } \\
\text { edge }\end{array}$ & $0.19(0.13,0.36)(12)$ & $0.23(0.10,0.35)(29)$ & 0.793 & $\begin{array}{l}0.17(0.12,0.31) \\
\quad(28)\end{array}$ & $\begin{array}{l}0.15(0.07,0.20) \\
\quad(19)\end{array}$ & 0.989 & 0.022 & 0.043 \\
\hline $\begin{array}{c}\text { Scaffolded } \\
\text { segment }\end{array}$ & $0.35(0.20,0.38)(14)$ & $0.19(0.09,0.29)(44)$ & 0.001 & $\begin{array}{l}0.16(0.12,0.22) \\
\quad(41)\end{array}$ & $\begin{array}{l}0.15(0.10,0.20) \\
\quad(36)\end{array}$ & 0.391 & 0.064 & 0.410 \\
\hline Distal edge & $0.14(0.08,0.31)(9)$ & $0.15(0.06,0.28)(28)$ & 0.739 & $\begin{array}{l}0.10(0.04,0.26) \\
(29)\end{array}$ & $\begin{array}{l}0.19(0.11,0.26) \\
\quad(25)\end{array}$ & 0.675 & 0.771 & 0.445 \\
\hline
\end{tabular}

$P_{1}$ denotes the significance of difference between the strain values estimated before and immediate after device implantation; $P_{2}$ the significance of difference between the strain values at post-scaffold implantation and at short-term follow-up; $P_{3}$ the significance of difference between the strain values at post-scaffold implantation and at mid-term follow-up; and $P_{4}$ the significance of differences of the strain values at the two followup time points

The number in the parenthesis at the left side of each column indicates the number of segments analyzed at each time point

properties of the vessel wall. We found that in contrast to the first generation which has a transient effect on vessel wall strain, the updated revision Absorb BVS 1.1 causes a permanent decrease of the strain values at the treated segment without affecting the mechanical properties of the proximal and distal edge $[5,6]$.

The reduction of the vessel wall strain noted immediately after Absorb BVS 1.0 or after Absorb BVS 1.1 deployment has been attributed to the shielding effect of the device, and to fact that the foreign material is likely to interfere with the palpographic estimations due to the artifactual acoustic properties of the struts [5, 6, 12]. In the first revision Absorb BVS the change in the strain values at the treated vessel was temporary as at 6 months and 24 months follow-up the measured strain was increased and approached the strain estimated before device 
Table 3 Strain values at the proximal edge, the scaffolded segment and the distal edge before device implantation, immediately after device deployment, at short-term and at mid-term follow-up in patients who had serial palpographic examination immediate after scaffold implantation and at the two follow-up time points

\begin{tabular}{|c|c|c|c|c|c|c|}
\hline & $\begin{array}{l}\text { Post-scaffold implantation } \\
(\mathrm{n}=20)\end{array}$ & $\begin{array}{l}\text { Short term follow-up } \\
(\mathrm{n}=20)\end{array}$ & $\begin{array}{l}\text { Mid-term follow-up } \\
(\mathrm{n}=20)\end{array}$ & $P_{1}$ & $P_{2}$ & $P_{3}$ \\
\hline Proximal edge & $0.25(0.13,0.33)(12)$ & $0.15(0.07,0.23)(12)$ & $0.16(0.09,0.22)(12)$ & 0.278 & 0.135 & 0.817 \\
\hline $\begin{array}{c}\text { Scaffolded } \\
\text { segment }\end{array}$ & $0.20(0.12,0.29)(20)$ & $0.14(0.08,0.20)(20)$ & $0.15(0.10,0.19)(20)$ & 0.048 & 0.024 & 0.922 \\
\hline Distal edge & $0.11(0.04,0.23)(12)$ & $0.11(0.06,0.31)(12)$ & $0.20(0.11,0.24)(12)$ & 0.880 & 0.874 & 0.692 \\
\hline
\end{tabular}

$P_{1}$ denotes the significance of difference between the strain values at post-scaffold implantation and at short-term follow-up; $P_{2}$ the significance of difference between the strain values at post-scaffold implantation and at mid-term follow-up; and $P_{3}$ the significance of differences of the strain values at the two follow-up time points

The number in the parenthesis at the left side of each column indicates the number of segments analyzed at each time point

Fig. 2 Changes in vessel wall strain $(\mathrm{ROC} / \mathrm{mm})$ at the proximal edge the scaffolded segment and the distal edge in patients who had serial palpographic examination immediately after scaffold implantation at short-term and mid-term follow-up. $R O C$ Rotterdam classification

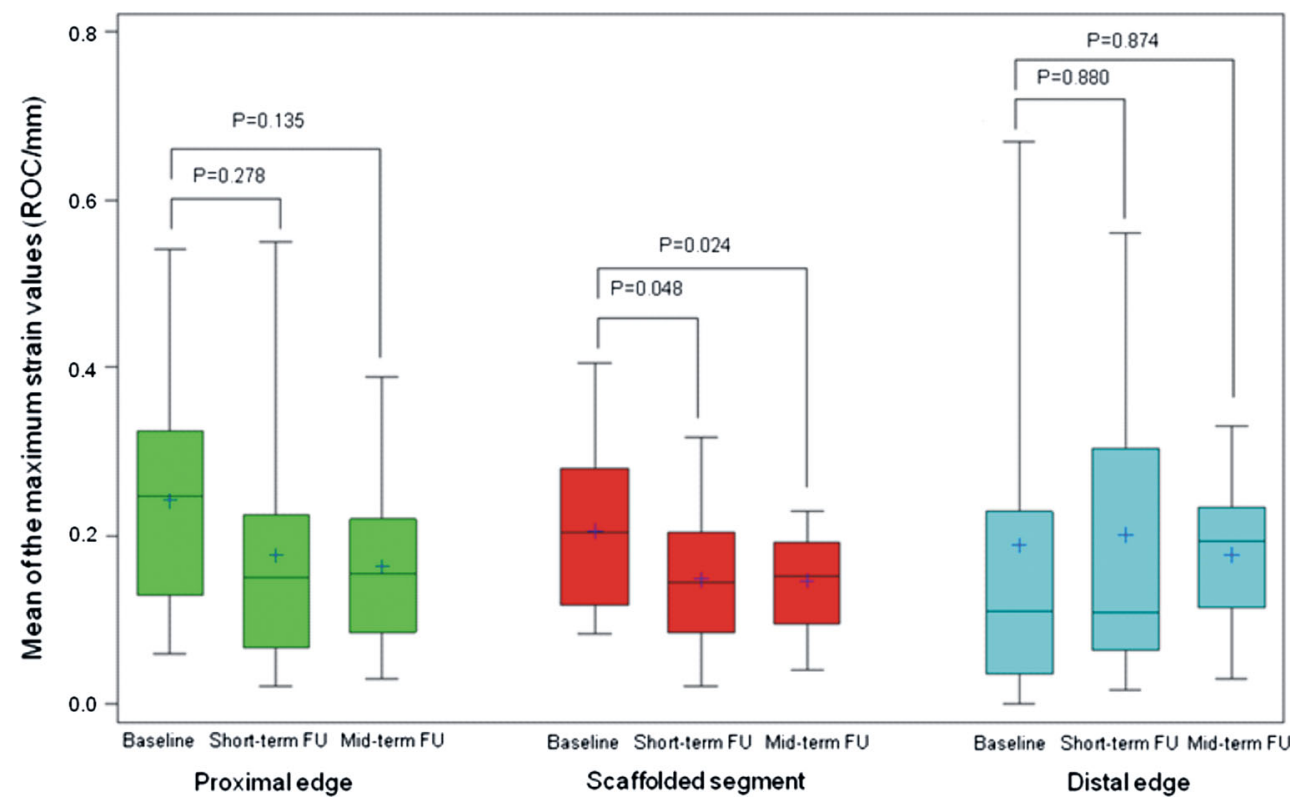

Furthermore, we have recently demonstrated that in Absorb BVS 1.1 a thick layer of neointimal tissue develops (mean thickness 210-220 $\mu \mathrm{m}$ at short-term follow-up) that covers the entire circumference of the vessel shielding the underlying plaque [16]. Histology studies in porcine models have shown that the neointima tissue consists of smooth muscles cells and fibrous tissue and thus the superficial plaque is anticipated to exhibit low strain values in a palpographic examination $[2,3,17]$. Indeed the strain values reported in our analysis at short- and mid-term follow-up are close to the strain measured in fibrotic plaques by Korte et al. [3] using elastography in pig models. It appears that the second revision Absorb BVS 1.1 modifies permanent the mechanical properties of the superficial plaque by altering its phenotype to a more stable form (Fig. 3). Our findings indicate that in contrast to the metallic stents, which are anticipated to have a similar effect on the mechanical properties of the vessel wall, in bioresorbable scaffolds minor changes in their design are 

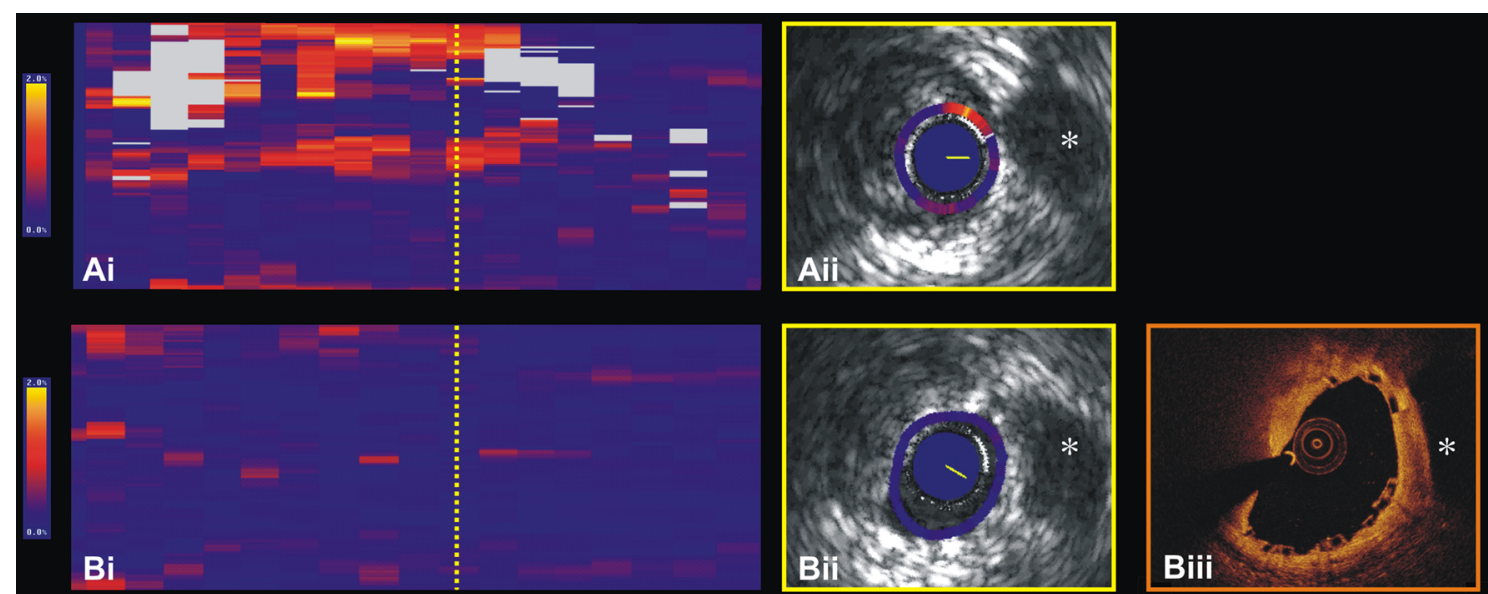

$\mathrm{Bi}$
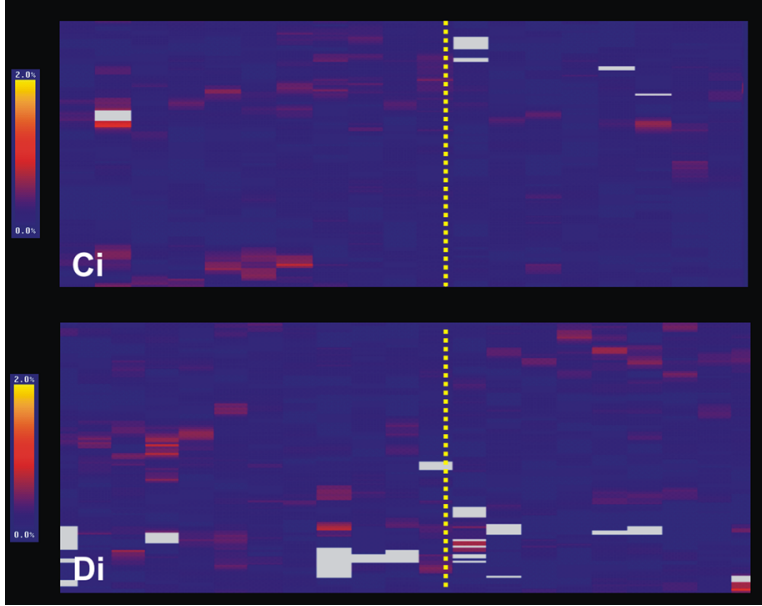

Fig. 3 Spread out plot of the vessel wall strain at baseline before Absorb BVS implantation (Ai), immediate after scaffold deployment (Bi), at short-term (Ci), and mid-term follow-up (Di). The blue color indicates low strain values where the red/yellow a high strain. It is apparent that the incidence of the high strain values decreased immediate after scaffold deployment and it is even lower at short-and mid-term follow-up. Panels Aii, Bii, Cii and Dii portray corresponding IVUS cross-sections acquired at baseline before and immediate after scaffold deployment, at short-term, and at mid-term follow-up respectively. The position of these frames in the spread-out vessel plots is indicated with a yellow line. High strain values are noted at the shoulders of an echolucent plaque before scaffold implantation

likely to have detrimental implications on vessel wall strain. Thus the results of this analysis cannot be extrapolated to other scaffolds even to these with a similar design and composition.

The effect of the decreased strain on vessel wall pathophysiology is yet unknown. Several studies have demonstrated that the ability of the vessel wall to expand as a response to a pulsatile cyclic strain has an athero-protective role as it stimulates eNOS gene regulation, promotes prostacyclin synthesis and maintains the contractile phenotype of the smoothes muscles cells [18-20]. However, plaques exhibiting low strain such as the pathological
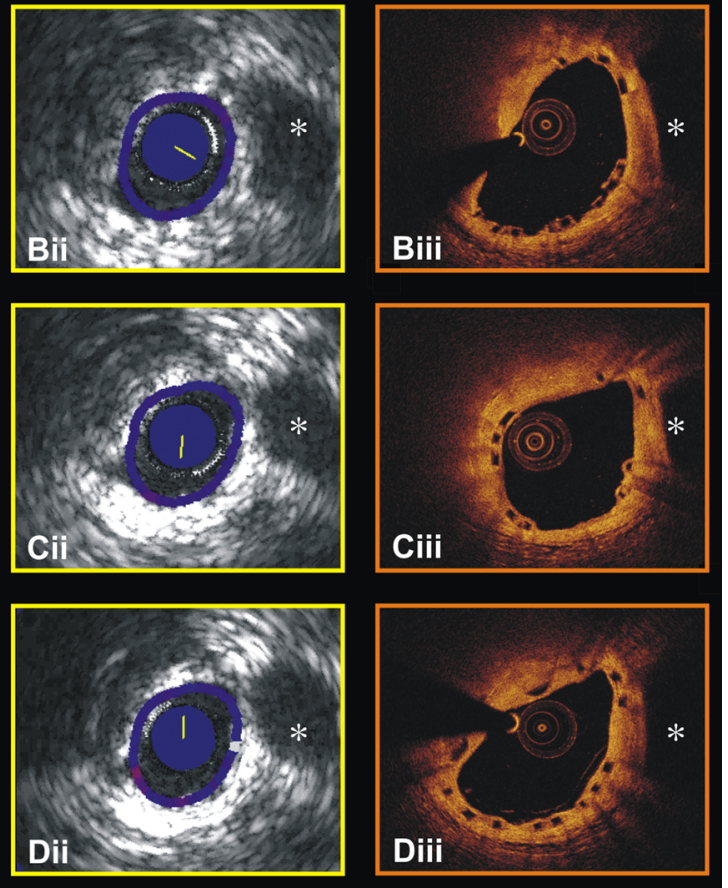

(Aii), however immediate after device deployment the strain values are low in the entire circumference of the lumen (Bii). OCT imaging performed after scaffold deployment this time point (Biii) indicates the presence of a lipid rich plaque (the correspondence between IVUS and OCT is shown with an asterisk). The strain values remain low at short- and mid-term follow-up in the IVUS cross-section (panels Cii and Dii respectively). OCT performed at the follow-up time points shows that neointima tissue has been developed that sealed the underlying plaque. The mean thickness of the neointima tissue is measured $150 \mu \mathrm{m}$ at short-term and $220 \mu \mathrm{m}$ at mid-term follow-up (Supplementary figure)

intimal thickening appear stable and rarely cause future events, while the plaques that demonstrate a high strain are associated with increased vulnerability $[1,4,21]$. Therefore it can be argued that the low strain estimated in stable plaques is sufficient for the stimulation of the pulsatile cyclic strain-dependent athero-protective mechanisms and for triggering the necessary mechanotransduction and pathophysiogical pathways that prevent plaque progression. In Absorb BVS this argument is supported by histology studies showing that in scaffolded segments the smooth muscles cells maintain their benign contractile phenotype, and by clinical reports demonstrating 
restoration of the endothelial dependent vasomotion at 1 year follow-up, suggesting a functionally normal endothelium that is capable to respond to chemical and mechanical stimuli [15, 22].

Although palpography appears unable to predict the natural history of a high risk plaque there is robust evidence to support that the mechanical properties of the vessel wall provide useful prognostic information since patients with high strain plaques are more likely to experience acute coronary events comparing to those with low strain lesions [1, 4]. Furthermore, the Integrated Biomarkers and Imaging Studies I and II have shown that an aggressive pharmaceutical treatment reduces local strain values, whereas the vShield Evaluated at Cardiac hospital in Rotterdam for Investigation and Treatment of TCFA (SECRITT) trial that implemented a self-expanding stent to seal high risk plaques have demonstrated a significant decrease of the strain values immediate after device deployment [7-9]. Our results are similar to what has been reported to metallic stents, showing that Absorb BVS 1.1 implantation changes permanently the mechanical properties of the vessel wall and stabilizes the plaque. However, further palpographic data after the full resorption of the BVS are needed to confirm this statement and further research and robust data from randomized control trials are required before advocating the use of these devices for the invasive sealing of vulnerable, prone-to-rupture plaques $[16,23,24]$.

\section{Limitations}

A major limitation of the current study is the fact that a considerable number of patients did not have serial palpographic examination. Thus, we included all the data that were available from each patient acknowledging the fact that missing examinations can affect the reported results. To confirm the findings of our initial analysis we also performed a sub-analysis including the patients who had truly serial examinations. Although the number of patients in the sub-analysis was small the agreement noted between the results of the initial analysis and the subanalysis with regards the scaffolded segment allows us to report these findings with some certainty. Another limitation of our analysis was the lack of a control group with serial palpographic examination that would allow us to compare the reported changes in the vessel wall stain in the scaffolded segments with these in native untreated arteries.

Unfortunately OCT was an optional examination in the ABSORB Cohort B study and thus only very few patients $(\mathrm{n}=4)$ had serial palpographic and OCT assessment. Thus we were unable to combine these data and examine the association between the changes in the measured strain at follow-up and the neointimal thickness as well as the effect of the different plaque characteristics (i.e., composition of the plaque, thickness of the fibrous tissue over calcific and lipid tissue, extent of the lipid and calcific tissue, plaque burden and eccentricity) on this relation [25, 26].

\section{Conclusions}

This study for the first time investigated the mid-term implications of the second revision Absorb BVS on the mechanical properties of the plaque. We found that in contrast to the first revision where the strain values of the treated segment change temporarily, in the second revision the strain of the vessel wall gradually decreases with time. Long-term clinical follow-up data and evidence from randomized studies are required in order to examine the clinical implications of these findings.

Acknowledgments Christos V. Bourantas is funded by the Hellenic Heart Foundation.

Conflict of interest Xingyu Gao is employee of Abbott Vascular. None of the other authors have any conflict of interest to declare.

\section{References}

1. Schaar JA, Regar E, Mastik F et al (2004) Incidence of highstrain patterns in human coronary arteries: assessment with threedimensional intravascular palpography and correlation with clinical presentation. Circulation 109(22):2716-2719

2. Schaar JA, De Korte CL, Mastik F et al (2003) Characterizing vulnerable plaque features with intravascular elastography. Circulation 108(21):2636-2641

3. de Korte CL, Sierevogel MJ, Mastik F et al (2002) Identification of atherosclerotic plaque components with intravascular ultrasound elastography in vivo: a Yucatan pig study. Circulation 105(14):1627-1630

4. Brugaletta S, Garcia-Garcia HM, Serruys PW et al (2012) Relationship between palpography and virtual histology in patients with acute coronary syndromes. JACC Cardiovasc Imaging 5(3Suppl):S19-S27

5. Serruys PW, Ormiston JA, Onuma Y et al (2009) Abioabsorbable everolimus-eluting coronary stent system (ABSORB): 2-year outcomes and results from multiple imaging methods. Lancet 373(9667):897-910

6. Brugaletta S, Gogas BD, Garcia-Garcia HM et al (2012) Vascular compliance changes of the coronary vessel wall after bioresorbable vascular scaffold implantation in the treated and adjacent segments. Circ J 76(7):1616-1623

7. Van Mieghem CA, McFadden EP, de Feyter PJ et al (2006) Noninvasive detection of subclinical coronary atherosclerosis coupled with assessment of changes in plaque characteristics using novel invasive imaging modalities: the integrated biomarker and imaging study (IBIS). J Am Coll Cardiol 47(6):1134-1142

8. Serruys PW, Garcia-Garcia HM, Buszman P et al (2008) Effects of the direct lipoprotein-associated phospholipase $A(2)$ inhibitor 
darapladib on human coronary atherosclerotic plaque. Circulation 118(11):1172-1182

9. Wykrzykowska JJ, Diletti R, Gutierrez-Chico JL et al (2012) Plaque sealing and passivation with a mechanical self-expanding low outward force nitinol vShield device for the treatment of IVUS and OCT-derived thin cap fibroatheromas (TCFAs) in native coronary arteries: report of the pilot study vShield Evaluated at Cardiac hospital in Rotterdam for Investigation and Treatment of TCFA (SECRITT). EuroIntervention 8(8):945-954

10. Serruys PW, Onuma Y, Ormiston JA et al (2010) Evaluation of the second generation of a bioresorbable everolimus drug-eluting vascular scaffold for treatment of de novo coronary artery stenosis: six-month clinical and imaging outcomes. Circulation 122(22):2301-2312

11. Schaar JA, van der Steen AF, Mastik F et al (2006) Intravascular palpography for vulnerable plaque assessment. J Am Coll Cardiol 47(8 Suppl):C86-C91

12. Garcia-Garcia HM, Gonzalo N, Pawar R et al (2009) Assessment of the absorption process following bioabsorbable everolimuseluting stent implantation: temporal changes in strain values and tissue composition using intravascular ultrasound radiofrequency data analysis. A substudy of the ABSORB clinical trial. EuroIntervention 4(4):443-448

13. Tanimoto S, Bruining N, van Domburg RT (2008) Late stent recoil of the bioabsorbable everolimus-eluting coronary stent and its relationship with plaque morphology. J Am Coll Cardiol 52(20):1616-1620

14. Gomez-Lara J, Brugaletta S, Diletti R et al (2011) A comparative assessment by optical coherence tomography of the performance of the first and second generation of the everolimus-eluting bioresorbable vascular scaffolds. Eur Heart J 32(3):294-304

15. Serruys PW, Onuma Y, Dudek D et al (2011) Evaluation of the second generation of a bioresorbable everolimus-eluting vascular scaffold for the treatment of de novo coronary artery stenosis: 12-month clinical and imaging outcomes. J Am Coll Cardiol 58(15):1578-1588

16. Brugaletta S, Radu MD, Garcia-Garcia HM et al (2012) Circumferential evaluation of the neointima by optical coherence tomography after ABSORB bioresorbable vascular scaffold implantation: can the scaffold cap the plaque? Atherosclerosis 221(1):106-112
17. Onuma Y, Serruys PW, Perkins LE et al (2010) Intracoronary optical coherence tomography and histology at 1 month and 2,3, and 4 years after implantation of everolimus-eluting bioresorbable vascular scaffolds in a porcine coronary artery model: an attempt to decipher the human optical coherence tomography images in the ABSORB trial. Circulation 122(22):2288-2300

18. Peng X, Haldar S, Deshpande S et al (2003) Wall stiffness suppresses Akt/eNOS and cytoprotection in pulse-perfused endothelium. Hypertension 41(2):378-381

19. Gupta V, Grande-Allen KJ (2006) Effects of static and cyclic loading in regulating extracellular matrix synthesis by cardiovascular cells. Cardiovasc Res 72(3):375-383

20. Schad JF, Meltzer KR, Hicks MR et al (2011) Cyclic strain upregulates VEGF and attenuates proliferation of vascular smooth muscle cells. Vasc Cell 3:21

21. Stone GW, Maehara A, Lansky AJ et al (2011) A prospective natural-history study of coronary atherosclerosis. N Engl J Med 364(3):226-235

22. Serruys PW, Garcia-Garcia HM, Onuma Y (2012) From metallic cages to transient bioresorbable scaffolds: change in paradigm of coronary revascularization in the upcoming decade? Eur Heart $\mathrm{J}$ 33(1):16-25

23. Bourantas CV, Farooq V, Zhang Y, et al. (2013) Circumferential distribution of the neointima at 6 months and 2 years follow-up after a bioresorbable vascular scaffold implantation. A substudy of the ABSORB Cohort B Clinical Trial EuroIntervention (In press)

24. Stone GW (2013) Rationale and design of PROSPECT II. 11 Vulnerable Plaque Meeting, Paris, France, 23-26 June 2013

25. Imoto K, Hiro T, Fujii $\mathrm{T}$ et al (2005) Longitudinal structural determinants of atherosclerotic plaque vulnerability: a computational analysis of stress distribution using vessel models and three-dimensional intravascular ultrasound imaging. J Am Coll Cardiol 46(8):1507-1515

26. Kumar RK, Balakrishnan KR (2005) Influence of lumen shape and vessel geometry on plaque stresses: possible role in the increased vulnerability of a remodelled vessel and the "shoulder" of a plaque. Heart 91(11):1459-1465 